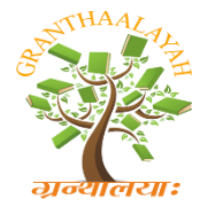

\author{
INTERNATIONAL JOURNAL OF RESEARCH - \\ GRANTHAALAYAH \\ A knowledge Repository
}

Social

\title{
A STUDY ON LOCUS OF CONTROL AND SELF CONFIDENCE OF HIGH SCHOOL STUDENTS
}

\author{
Y. Vanaja ${ }^{1}$, D. Geetha ${ }^{2}$ \\ ${ }^{1}$ M.Sc M. Ed Scholar, RVS College of Education Sulur, India \\ ${ }^{2}$ M.A, M. Ed Assistant Professor in Pedagogy of English, RVS College of Education Sulur, India
}

\begin{abstract}
Locus of control refers to an individual's perception of main causes of events in life. More simply, do you believe that your destiny is controlled by yourself that your destiny is controlled. Self - confidence is an essential part of humanity. Self - confidence is the internal sense, or belief that we can accomplish a variety of tasks or goals throughout life. Self - confidence is similar, but more related to believing we are generally competent in what we do, and that we deserve to be happy in life. A person with self-confidence generally likes herself, is willing to take risks to achieve her personal and professional goals, and thinks positively about the future. Self - confidence is something that you can build on your own! One of the major objectives of this study is to investigate self-confidence and locus of control in a cross-cultural context. Selected high school students from Government School, Private School and Government Aided School in Coimbatore District will be compared on self-confidence and locus of control. In addition, relationships of these psychological variables with academic achievement and with each other will also be examined. An examination of sex differences, as an independent variable, will also be investigated. The sample 300 high school students. Locus of control is another important and popular concept. Its construct has been the subject of psychological research since the late 1950s. Interest in the study started with Rotter's (1966) monograph, which presented the concept of locus of control from social learning theory point of view.
\end{abstract}

Keywords: Self Confidence; Students; Investigate; Schools.

Cite This Article: Y. Vanaja, and D. Geetha. (2017). "A STUDY ON LOCUS OF CONTROL AND SELF CONFIDENCE OF HIGH SCHOOL STUDENTS." International Journal of Research - Granthaalayah, 5(7), 598-602. 10.29121/granthaalayah.v5.i7.2017.2167.

\section{Introduction}

Locus of control refers to an individual's perception of main causes of events in life. More simply, do you believe that your destiny is controlled by yourself that your destiny is controlled. Self - confidence is an essential part of humanity. Self - confidence is the internal sense, or belief that we can accomplish a variety of tasks or goals throughout life. Self - confidence is similar, but more related to believing we are generally competent in what we do, and that we deserve to be 
happy in life. A person with self-confidence generally likes herself, is willing to take risks to achieve her personal and professional goals, and thinks positively about the future. Self confidence is something that you can build on your own! One of the major objectives of this study is to investigate self-confidence and locus of control in a cross-cultural context. Selected high school students from Government School, Private School and Government Aided School in Coimbatore District will be compared on self-confidence and locus of control. In addition, relationships of these psychological variables with academic achievement and with each other will also be examined. An examination of sex differences, as an independent variable, will also be investigated. The sample 300 high school students. Locus of control is another important and popular concept. Its construct has been the subject of psychological research since the late 1950s. Interest in the study started with Rotter's (1966) monograph, which presented the concept of locus of control from social-learning theory point of view.

\section{Objectives of the Study}

Objectives are the main areas where the investigator will be conducting the study work. There are two main types of objectives undertaken by the investigator in this study work. The purpose of the present study is to find out locus of control and self confidence and high school students in relation to Gender, locality, medium of study, type of school and overall high school.

\subsection{General Objectives}

A Study on locus of control and self-confidence and high school students

\subsection{Specific Objectives}

- Find out the level of locus of control of high school students.

- To find out the level of self-confidence of high schools students.

- To find out the relationship between locus of control and self - confidence of high schools students.

\section{HYPOTHESIS 1:}

There is no significant difference among the students in their locus of control and self-confidence with respect to their medium of instruction.

Table 1: " $t$ " value among the students in their locus of control and self-confidence with respect to their medium of instruction

\begin{tabular}{|l|l|l|l|l|l|}
\hline Medium & Number & Mean & S.D & t-value & Remarks \\
\hline Tamil & 96 & 1.97 & 0.14 & 0.10 & N.S \\
\cline { 1 - 4 } English & 204 & 1.90 & 0.20 & & \\
\hline
\end{tabular}

\section{INFERENCE:}

Since the calculated value (0.10) is less than the table value of ' $t$ ' (1.98), the null hypothesis is accepted. It is inferred from the above table that there is no significant difference among the students in their locus of control and self-confidence with respect to their medium of instruction 


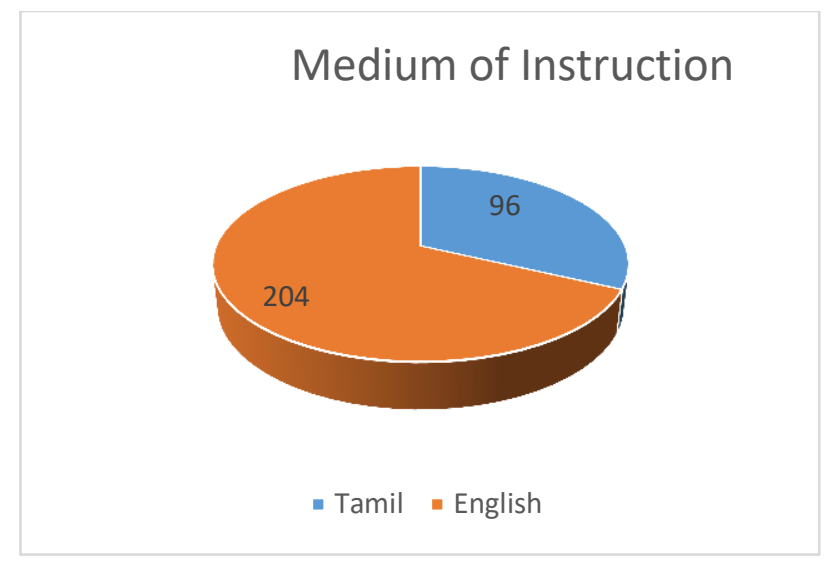

\section{HYPOTHESIS 2:}

There is no significant difference among boys and girls students in their locus of control and selfconfidence.

Table 2: "t" value among boys and girls students in their locus of control and selfconfidence.

\begin{tabular}{|l|l|l|l|l|l|}
\hline Gender & Number & Mean & S.D & t-value & Remarks \\
\hline Boys & 187 & 1.93 & 0.16 & 0.08 & N.S \\
\hline Girls & 113 & 1.91 & 0.19 & & \\
\hline
\end{tabular}

\section{INFERENCE:}

Since the calculated value (0.08) is less than the table value of ' $t^{\prime}(1.93)$, the null hypothesis is accepted. It is inferred from the above table that there is no significant difference among boys and girls students in their locus of control and self-confidence.

\section{Respondents in Gender Wise}

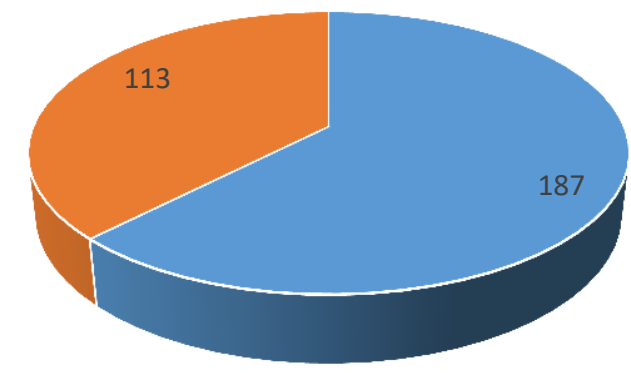

- Male - Female

\section{HYPOTHESIS 3:}

There is no significant difference among the students in their locus of control and self-confidence with respect to their type of school. 


\begin{tabular}{|l|r|l|l|c|l|}
\hline Source of variance & \multicolumn{1}{|c|}{ df } & Sum square & Mean square & F & Remarks \\
\hline Between Group & 3 & 1.71 & 0.85 & 1.97 & N.S \\
\cline { 1 - 4 } With in group & 297 & 128.67 & 0.43 & & \\
\cline { 1 - 3 } TOTAL & 300 & & & & \\
\hline
\end{tabular}

\section{INFERENCE:}

Since the calculated value of "F" (1.97) is less than the table value of "F" $(0.05)$ which holds 3.04, the Null hypothesis is accepted .It is inferred from the above table that there is no significant difference among the students in their locus of control and self-confidence with respect to their type of school.

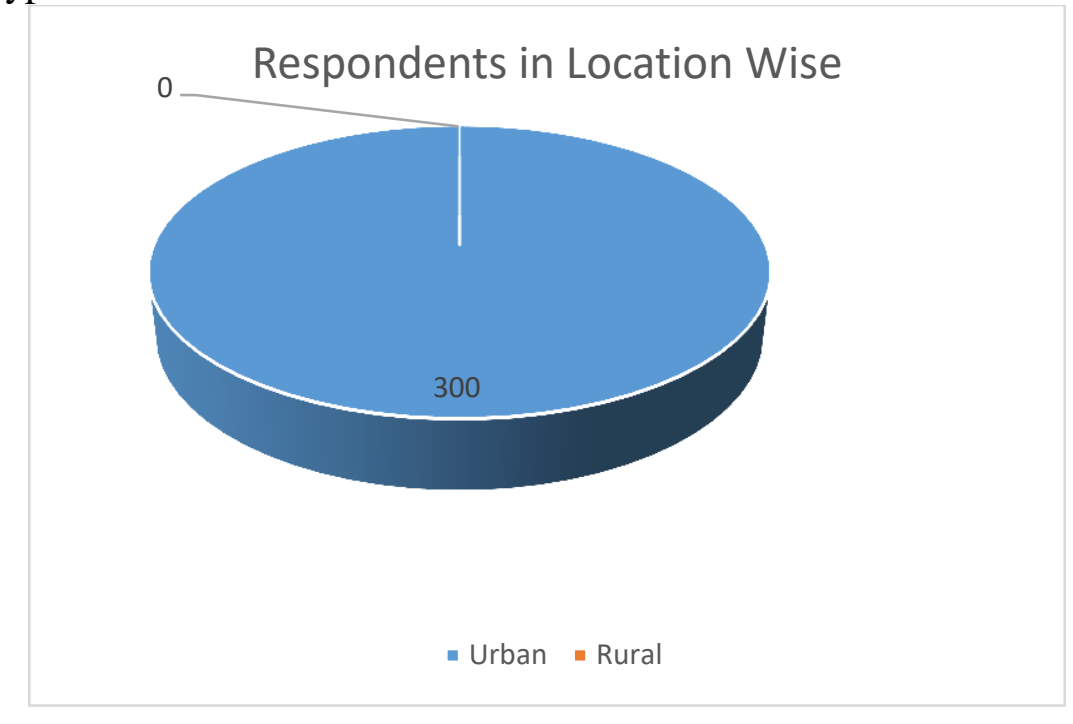

\section{Conclusion}

Finding the calculated value (0.10) is less than the table value of 't' (1.93), the null hypothesis is accepted. It is inferred from the above table that there is no significant difference among the students in their locus of control and self-confidence with respect to their medium of instruction. It is inferred from the above table that there is no significant difference among the students in their locus of control and self-confidence with respect to their type of school.

\section{References}

[1] Abdallah, T. M. (1989a). A cross cultural study of self-confidence and locus of control. Unpublished D.Phil. thesis. University of York.

[2] Abdallah, T. M. (1989b). Self-confidence and locus of control of college men in Saudi Arabia. Psychological Reports. 65, 1323-1326.

[3] Bachman, J. G. (1970). Youth in Transition. Vol. 2, University of Michigan: Institute for Social Research.

[4] Bachman, J. G., \& O'malley, P. M. (1977). Self-confidence in young men. Journal of Personality and Social Psychology. 35, 365-380.

[5] Carment, D. W. (1974). Internal vs. external control in India and Canada. International Journal of Psychology. 9, 45-50. 
[6] Carr, M., Borkowski, J. G., \& Maxwell, S. E. (1991). Motivational components of underachievement. Developmental Psychology. 27. 1, 108- 118.

[7] Bush PJ, Iannotti RJ: The development of children's health orientations and behaviors: Lessons for substance use prevention. Ntl Inst. on Drug Abuse Research Monogor Ser 56:45-74,1985.

[8] Flay BR: Psychosocial approaches to smoking prevention: A review of findings. Health Psychol 4:449-488, 1985.

[9] Jessor R.: Marihuana: A review of recent psychosocial research, in RI Dupont, A Goldstein and J O'Donnell (eds): Handbook on Drug Abuse. Washington, DC, NIAAA, 1979.

[10] Lewis CE, Lewis MA: Improving the health of children: Must the children be involved? Annu Rev Public Health 4:259-283, 1983.

*Corresponding author.

E-mail address: anslam2009@ gmail.com 